\title{
Mobile phones of health care workers are potential vectors of nosocomial agents
}

\author{
Emmanuel Chike Amadi ${ }^{1}$, Tochukwu Nwamaka Nwagu ${ }^{2 \star}$ and Vera Emenuga ${ }^{3}$ \\ ${ }^{1}$ Department of Medical Microbiology, College of Medicine, Enugu State University of Science and Technology, Enugu, \\ Nigeria. \\ ${ }^{2}$ Department of Microbiology, University of Nigeria, Nsukka, Enugu State, Nigeria. \\ ${ }^{3}$ Department of Medical Laboratory Sciences, University of Nigeria, Enugu Campus, Enugu, Enugu State, Nigeria.
}

Accepted 21 May, 2013

\begin{abstract}
Mobile phones have become necessary companions to most health care personnel and have been implicated as reservoirs of known nosocomial agents. This study was carried out to determine the type and frequency of microorganisms' contaminating mobile phones of health workers in a University Teaching Hospital in Nigeria. Swabs of $\mathbf{5 0}$ mobile phones were collected and cultured, and contaminants characterized. Forty three (86\%) out of 50 mobile phones were positive for microbial contamination. Samples from doctors and medical students had $100 \%$ contamination and samples from nurses $70 \%$. Six clinically important microorganisms were found. Staphylococcus sp was most predominant and constituted $30.2 \%$ while $P$. aeruginosa made up $14 \%$ and Klebsiella sp, $9.3 \%$ of the entire isolates. Given the frequent occurrence of potential pathogens as contaminants, there is the need for strict adherence to proper sanitary measures by all who operate in the hospital environment to avoid dissemination of pathogenic agents.
\end{abstract}

Key words: Mobile phones, contamination, health care workers, nosocomial agent.

\section{INTRODUCTION}

Nosocomial infections are defined as infections resulting from pathogens acquired by patients while in the hospital or other clinical care facilities, these infections appear during hospitalization or after discharge (Kouchak and Askarian, 2012). These infections could also affect the health care staff and visitors to the facility (Meltzer, 2003). According to Meltzer (2003), there is possibility of spillover of nosocomial infections outside the hospital to the environment and the community at large. Nosocomial infections have been a cause of much concern amongst the hospital personnel especially considering the increasing number of hospital related infections as a result of multi drug resistant microbial strains (Ginocchio, 2002). Most worrisome is the fact that in spite of advances in modern medicine, risks of morbidity and mortality amongst hospi- talized patients is as high as $40 \%$ though precise data on developing countries is limited (Rajesh and Rattan, 2008). Numerous genera and species of bacteria, viruses, and fungi including Staphylococcus aureus, Escherichia coli, Klebsiella spp, Enterococcus spp and Proteus spp are noted as etiologic agents of nosocomial infections. These agents vary between hospitals and geographical locations depending on the type of infection as well as the environmental predisposing factors found in a given area (Struelens et al., 2004). Infectious sources are grouped into exogenous and endogenous sources. Exogenous sources include stethoscopes, bronchoscopes, pagers, pens, ball-point biros, patients hospital charts and laboratory report forms, computer keyboards, ventilators, respiratory equipments, endoscopes, wash bowls, bed pans, 
Table 1. Microbial contamination of mobile phones of health care workers.

\begin{tabular}{llc}
\hline Group & Examined & Growth present (per group) \\
\hline Doctors & 15 & $15(100)$ \\
Nurses & 10 & $7(70)$ \\
Pharmacists & 5 & $2(5)$ \\
Physiotherapists & 5 & $4(5)$ \\
Medical students & 5 & $5(100)$ \\
Lab. Technologists & 10 & $10(100)$ \\
Overall & 50 & $43(84)$ \\
\hline
\end{tabular}

Numbers in brackets represent percentage growth present.

patents' beds and clothing, curtains, catheters, and very recently, mobile phones (Willey et al., 2009; Maley, 2000; Brandy, 2006; Borer et al., 2005).

According to Brady et al. (2006), handsets belonging to medical personnel including doctors, specialists and other health care workers are involved in the transmission of nosocomial infections in the health care systems. Bhattacharya (2005) indicated that the means of contamination of these handsets include the hands, inanimate objects around the hospital as well as other human activities. However, there is paucity of such literature originating from Nigeria. This study was carried out to determine the type and frequency of microorganisms' contaminating mobile phones of health workers in a University Teaching Hospital in Nigeria.

\section{MATERIALS AND METHODS}

\section{Hospital setting}

Enugu State University of Science and Technology (ESUT) Teaching Hospital is located in the capital city of Enugu State, Eastern Nigeria, with a population of more than one million people, and located approximately at $6^{\circ} 27^{\prime}$ north of latitude and $7^{\circ} 32^{\prime}$ east of longitude on the geographical map. ESUT and UNTH (University of Nigeria Teaching Hospital) located in the same city are the major source of medical care to the entire State and neighboring environs.

\section{Sample collection}

Swabs from 50 MPs of different randomly selected medical personnel of various departments comprising doctors (15), medical laboratory technologists (10), nurses (10), medical students on clinical laboratory training-year (5), pharmacists (5) and physiotherapists (5) were collected from staff of ESUT Teaching Hospital, Enugu. These were done during the official working hours $(8.00 \mathrm{am}$ to 4.00 $\mathrm{pm}$, that is, 07.00 to $15.00 \mathrm{GMT}$ ). The process of obtaining the swab samples were by rotating over the surface of both sides of each MP, held between two fingers, with sterile cotton tipped applicators (Sterilin, England) which had been earlier on aseptically moistened with sterile normal saline. All sampling were done in duplicates, and the sample size (50) reflects about 10 percentage of the study population. The concept of the study was explained to all subjects and their consent sought. Permission was earlier obtained from the Chief Medical Director of the institution about ethics and strict confidentiality.

\section{Isolation}

After swabbing, the cotton tipped applicators were each immediately aseptically inserted back into its tube to which $1 \mathrm{ml}$ of nutrient broth had been added and transported to the laboratory for analysis within $1 \mathrm{~h}$. In the laboratory, each of the tube was wellshaken for good mixing. Exactly $0.5 \mathrm{ml}$ of its nutrient broth sample was inoculated into $4.5 \mathrm{ml}$ peptone water. This was serially diluted using peptone water and $1 \mathrm{ml}$ of each was plated on freshly prepared nutrient and blood agar (Oxoid), labeled appropriately, and thereafter incubated aerobically at $37^{\circ} \mathrm{C}$ for 24 to $48 \mathrm{~h}$.

\section{Characterization and identification of isolates}

After the initial identification and the Gram staining using standard method, significant cultures were further characterized based on microscopic appearances and biochemical reactions. The motility of the isolated bacteria was examined by the "hanging drop technique." Their Gram reactions and cell morphology were examined from heat-fixed smears. Isolated microorganisms were identified to the appropriate genera (Cheesbrough, 2006).

\section{RESULTS}

The rate of bacterial contamination of the MPs from different groups of hospital staff was $86 \%$ (Table 1). Out of a total of $50 \mathrm{MPs}$ investigated, only 7 had no microbial growth. Among these were MPs belonging to nurses (3), pharmacists (3) and physiotherapists (1). From Table 1, it can also be seen that MPs which showed microbial contamination included all the samples collected from doctors (15/15), all samples from medical students (5/5) and all samples from Medical Laboratory technologists $(10 / 10)$. While $14 \%$ of the total samples showed no growth, $26 \%$ were contaminated with one bacterial specie; $45 \%$ with two different bacteria species and $15 \%$ with three or more different species. A total of six potential clinically relevant microorganisms were isolated and these include S. aureus, E. coli, Pseudomonas aeruginosa, Enterobacter aerogenes, Klebsiella aerogenes and Proteus mirabilis. However, coagulase-negative Staphyloccus, S. epidermidis were also isolated. Subsequent analysis showed that amongst the 43 MPs contaminated by bacteria, frequency of the potentially clinical isolates were $13(30.2 \%)$ for $S$. aureus, $9(20.9 \%)$ for $P$. aeruginosa, $6(14.0 \%)$ for $P$. 


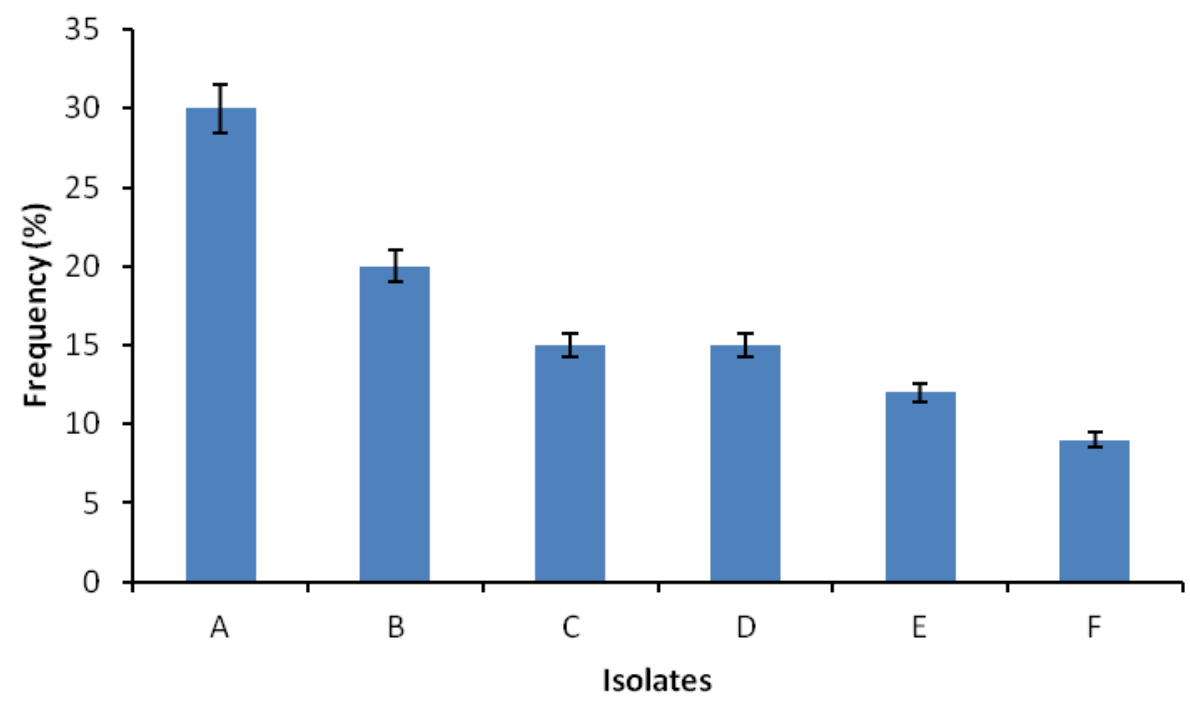

Figure 1. Frequency of different bacteria isolated from mobile phones of health care workers. $\mathrm{A}=\mathrm{S}$. aureus; $\mathrm{B}=P$. aeruginosa; $\mathrm{C}=$ Proteus; $\mathrm{D}=\mathrm{E}$. coli; $\mathrm{E}=$ Enterobacter; $\mathrm{F}$ $=$ Klebsiella.

Table 2. Prevalence of bacteria from mobile phones of different health care workers.

\begin{tabular}{lcccccc}
\hline \multirow{2}{*}{ Isolate } & \multicolumn{7}{c}{ Prevalence (\%) } \\
\cline { 2 - 7 } & Doctors & Nurses & Lab Tech. & Pharm. & Phy. Therap. & Med. Stud. \\
\hline Staphylococcus sp & 30.8 & 10.4 & 8.2 & 15.4 & 20.4 & 15.4 \\
E. coli & 33.3 & 16.7 & - & - & 16.7 & 33.3 \\
P. aeruginosa & 22.2 & 22.2 & 55.6 & - & - & - \\
Enterobacter $\mathrm{sp}$ & 60 & 20 & 20 & - & - & - \\
Klebsiella sp & 100 & - & - & - & - & - \\
Proteus mirabilis & 16.7 & 66.7 & - & - & 16.7 & - \\
\hline
\end{tabular}

mirabilis, $6(14.0 \%)$ for E. coli, $5(11.6 \%)$ for $E$. aerogenes and $4(9.3 \%)$ for $K$. aerogenes (Figure 1). The highest occurrence of Staphylococcus species was seen amongst doctors $(30.8 \%)$ and physiotherapist $(20.1 \%)$ followed by pharmacists (15.4\%) and medical students (15.4\%) as seen in Table 2.

The percentage $E$. coli isolated from the groups were $33.3 \%$ each from doctors and medical students, and $16.7 \%$ each from nurses and physiotherapists. Frequency of $P$. aeruginosa isolates collected from MPs was $22 \%$ each for nurses and doctors. Sixty percent of the $E$. aerogenes and $100 \%$ Klebsiella sp isolated were from MPs belonging to doctors.

\section{DISCUSSION}

The majority of the MPs tested were found to be contaminated by one or more bacteria. Similarly, Srikanth et al. (2010) reported that out of 36 cell phones collected from health care workers in an Indian hospital, only 5 (6\%) showed no growth. Ulger et al. (2009) also reported the isolation of various microorganisms including noso- comial agents from $94.5 \%$ of the samples tested in a study conducted on various health care workers in a hospital. Based on a study carried out in Nigeria by Akinyemi et al., (2009) on the microbial contamination of MPs belonging to different groups of people including marketers and food vendors, lecturers and students, hospital workers and public servants; hospital workers were found to have the lowest rate $(15.3 \%)$. This was related to the activities and environment in which these groups operated. The present study is the first report on the rate of contamination of MPs between different groups of health personnel in Nigeria. Though, bacterial contamination rates of MPs in the community may be less than or similar to the rate in the hospital; antibiotic resistant strains are more predominant in hospital settings (Brady et al., 2009; Catano et al., 2012; Young et al., 2005). This study is therefore of crucial importance since MPs have become somewhat indispensable to most health personnel as they are now used for much more than make calls and have been associated to the reduction of medical error and injury (Soto et al., 2006).

MPs are used for checking time, for sourcing materials 
from the internet and for communicating with friends, colleagues and associates through various forums. MPs are carried in pockets, handbags or in the hands and taken along to ward rounds, theatres rooms and other units in the hospital or even to the rest rooms. During handling, MPs come in contact with different parts of the body including the face, mouth, ears, hands and skin contaminating and cross-contaminating these parts. The MPs owned by doctors had more contaminants (100\%) than that of nurses (70\%). Similarly, Goldblatt et al. (2007) reported that physician's cell phones had a higher incidence $(60 \%)$ of nosocomial pathogens than the nursing staff $(20 \%)$. Sadat-Ali et al. (2010) also reported that $40(51.3 \%)$ of 78 physicians' MPs were positive for bacteria compared with $41.8 \%$ of the nurses. According to previous studies, doctors wash their hands less frequently than nurses (Inweregbu et al., 2005) and this may be partly responsible for this occurrence. WienerWell et al. (2011) also reported high incidence of contamination of MPs of doctors, nurses and medical students during a study conducted in a 550-bed University affiliated hospital located in Israel. Of great concern is the extent of contamination of MPs belonging to doctors, nurses and medical students especially since these groups of people have direct contact with patients on regular basis. According to available report, nosocomial infections otherwise known as hospital acquired infections (HAls) affect over $25 \%$ of the total health care in developing countries (Tekerekoglu et al., 2011). Most common of these HAls are lower respiratory tract infections, surgical site infections and primary septicaemia (Singh and Purohit, (2012). HAls have been directly linked to bacterial contamination of equipments or the environment by health care workers (Hardy et al., 2006; Dancer et al., 2006). MPs, computer keyboards, curtains, white coats and ties can serve as reservoirs of bacterial pathogens (Catano et al., 2012).

According to a study by Rusin et al. (2002), surface-tohand transfer efficiencies of Gram positive bacteria (Micrococcus luteus), Gram negative bacteria (Serratia rubidea) and phage PRD-1 were 38.57 to $65.80 \%$ for phone receivers. Finger tip-to-mouth transfer efficiency rates were reported as 40.99 and $33.97 \%$ for the Gram positive and Gram negative bacteria, respectively. Staphylococcus spp were the predominant bacteria isolated in the present study. This is probably as a result of its predominance on different parts of the human body as normal flora and may be indicative of poor hand hygiene following consultation with patients. Though, the presence of coagulase negative Staphylococcus species is not significant, $S$. aureus is the most common gram +ve bacteria involved in nosocomial infections and is therefore of great concern (Inweregbu et al., 2005). Staphylococcus spp were isolated from MPs of all the groups tested. Brady et al. (2007) reported that $76.5 \%$ of 102 MPs sampled in Western General Hospital, Edinburgh were found to harbor coagulase-negative Staphylococci.
However, only $12(11.8 \%)$ demonstrated growth of pathogenic bacteria species. Similarly, Singh et al. (2010) also reported that the most dominant $(78 \%)$ bacteria isolated from MPs of dental personnel in an Indian clinic was coagulase-negative Staphylococcus. Brady et al. (2007) and Young et al. (2005) previously reported the colonization of hospital bed-control handsets by Methicllin resistant $S$. aureus and other microbial agents of nosocomial infections.

Presence of $E$. coli signifies fecal contamination of hands through bed pans or poor personal hygiene; this stresses the need for better sanitary measures amongst medical personnel. E. coli and $P$. aeruginosa are the most predominant Gram -ve bacteria involved in nosocomial infections (Gaynes and Edward, 2005). E. coli causes both gastrointestinal disease and extraintestinal infections such as pneumonia, meningitis, and bloodstream, urinary tract, abdominal and wound infections. $P$. mirabilis made up $15 \%$ of the isolates from this study and was mostly from laboratory technologists $(66.7 \%)$, nurses $(16.7 \%)$ and medical students (16.7\%). Tagoe et al. (2011) reported that $P$. mirabilis comprised $19 \%$ of bacterial isolates from 100 mobile phones randomly collected from University students in Ghana. Nosocomial infections are transmitted through direct and indirect contact or a combination of both routes (Eames, 2009). Fridkin and Gayres, (1999) reported that the frequency of direct hand contact between health workers and patients are higher in the intensive unit which leads to a higher risk of nosocomial infections. The fact that these organisms can persist in the environment increases the risk which they pose to patients and other immuno-compromised patients in the hospital environment. On inanimate objects, Staphylococcus spp is able to persist for 4 weeks to 7 months, Salmonella for $6 \mathrm{~h}$ to 4.2 years, Pseudomonas for $6 \mathrm{~h}$ to 16 months, Klebsiella for $2 \mathrm{~h}$ to 30 months, $E$. coli for 5 to 16 months and Enterococcus sp for 5 days to 14 months (Kramer et al., 2006; Kampf and Kramer, 2004).

Microbial contaminants on MPs can cross-contaminate the hospital environment through dry-dissemination (aerosolized as dry dust or particle) followed by absorption of moisture from the surrounding environment and this aids their survival and persistence in the environment (Eames et al., 2009; Cox, 1989). Survival of aerosolized Gram negative bacteria including Pseudomonas sp, Enterobacter sp and Klebsiella was found to be greatest in high relative humidity and low temperature (Marthi et al., 1990). Given the high humidity and cool conditions inside the hospital, pathogenic agents isolated from health personnel are therefore likely to persist in the environment for long periods of time unless specific measures are taken to de-contaminate the area. Though, Tekerekoglu et al. (2011) reported that patients, patientscompanions and visitors have higher tendency to carry infectious pathogens in the hospital environment, the risks posed by doctors and other health personnel cannot 
be ignored. Any strategy which could reduce the risk of nosocomial infections should be encouraged to minimize the spread of antibiotic resistant bacteria, its severe health effects, cost implications, and the associated morbidity and mortality rate. This is especially important in developing countries where majority of the patients do not have the income for prolonged hospital stays and generally give up on conventional health care methods when recovery rate is not as fast as expected.

To curb this menace, there is need for enlightenment. Hand hygiene has been applauded as the major way of reducing the spread of infection (Kampf and Kramer, 2004; Kennedy et al., 2003); and therefore, should be strictly adhered to by everyone in the hospital including care givers and patients (Hedin et al., 2012). Emphasis should be made on the observance of correct hygiene by all hospital staff especially doctors, nurses and medical students. This should include regular cleaning of personal items for example, stethoscopes, apparel, computer and MPs with $70 \%$ isopropyl alcohol to reduce/ prevent cross contamination (Singh et al., 2010; Hedin et al., 2012). Hospital environments should be regularly cleaned and disinfected to avoid spread from surface to surface, surface to air or vice versa (Rutala and Weber, 2004; Tang, 2009). There may be need to combine these strategies with the restriction of MPs in high risk areas.

\section{Conclusion}

It is obvious that MPs have become one of the reservoirs for nosocomial agents in the hospitals. Therefore, proper and adequate sanitary measures must be monitored to prevent spread of infectious agents between health care workers, patients and their visitors. Cleaning and proper handling of hospital MPs by all health personnel is relevant to curtail the spread of HAl. There is need for the doctors and other health workers to strictly adhere to 'proper hand hygiene' especially before and after attending to patients; and using the toilets. There is also need to restrict the use of MPs in high risk areas such as the intensive care unit as is done in some other parts of the world.

\section{REFERENCES}

Akinyemi KO, Atapu AD, Adetona OO, Coke RAO (2009). The potential role of mobile phones in the spread of bacterial infections. J. Infect. Dev. Ctries 3:628-632.

Bhattacharya $K$ (2005). Mobile phone and the surgeon-ls there a controversy? Ind. J. Surg. 67:53-54.

Borer Al, Gilad J, Smolyakov R (2005). Cell phones and Acinetobacter transmission. Emerg. Infect. Dis. 11:1160-1161.

Brady RR, Verran J, Damani NN, Gibb AP (2009). Review of mobile communication devices as potential reservoirs of nosocomial pathogens. J. Hosp. Infect. 71:295-300.

Brady RRW, Kalima P, Damani NN, Wilson RG, Dunlop MG (2007). Bacterial contamination of hospital bed-control handsets in a surgical set: a potential marker of contamination of the health care environment. Ann. R. Coll. Surg. Engl. 89:656-660.
Brady RRW, Wasson A, Stirling I, McAllister C, Damani NN (2006). Is your phone bugged? The incidence of bacterial phone to cause nosocomial infections on healthcare workers cell phone. J. Hosp. Infec. 62:123-125.

Brandy $\mathrm{R}$ (2006). A Communication problem: pointing a finger at mobile phones. Curr. Sci. 91: 7-11.

Catano JC, Echeverri LM, Szela C (2012). Bacterial contamination of clothes and environmental items in a third-level hospital in Colombia. Interdiscip. Perspect. Infect. Dis. Article ID 507640, doi:10.1155/2012/507640

Cheesbrough M (2006). District laboratory practices in tropical countries. Cambridge press. pp. 390-420.

Cox CS (1989). Airborne bacteria and viruses. Sci. Prog. 73:469-499.

Dancer SJ, Coyne M, Speekenbrink A, Samavedam S, Kennedy J, Wallace PG (2006). MRSA acquisition in an intensive care unit. Am. J. Infect. Control 34:10-7.

Eames I, Tang JW, Li Y, Wilson P (2009). Airborne transmission of disease in hospitals. J. R. Soc. Interface 6 Suppl 6 S697-S702.

Fridkin SK, Gaynes RP (1999). Antimicrobial resistance in intensive care units. Clin. Chest Med. 20:303-316.

Gaynes R, Edward JR (2005). Overview of nosocomial infections caused by Gram negative Bacilli. Clin. Infect. Dis. 41:848-854.

Ginocchio CC (2002). Roles of NCCLS in antimicrobial susceptibility testing and monitoring. Am. J. Health Pharm. 59: 7-11.

Goldblatt JG, Krief I, Klonsky T, Haller D, Milloul V, Sixsmith DM, et al (2007). Use of cellular telephones and transmission of pathogens by medical staff in New York and Israel. Infect. Control Hosp. Epidemiol. 28:500-503.

Hardy KJ, Oppenheim BA, Gossain S, Gao F, Hawkey PM (2006). A study of the relationship between environmental contamination with methicillin-resistant Staphylococcus aureus (MRSA) and patients' acquisition of MRSA. Infect. Control Hosp. Epidemiol. 27:127-132.

Hedin G, Blomkvist A, Janson M, Lindblom A (2012). Occurrence of potentially pathogenic bacteria on the hands of hospital patients before and after the introduction of patient hand disinfection. APMIS 120:802-807.

Inweregbu K, Dave J, Pittard A (2005). Nosocomial Infection. Contin. Educ. Anaesth. Crit. Care Pain 5(1):14-17.

Kampf G, Kramer A (2004). epidemiologic background of hand hygiene and evaluation of the most important agents for scrubs and rubs. Clin. Microbiol. Rev. 17: 863-893.

Kennedy KJ, Dreimanis DE, Beckingham WD, Bowden F J (2003). Staphylococcus aureus and Stethoscopes. Med. J. Aust. 178(9):468.

Kouchak F, Askarian M (2012). Nosocomial infections: The definition criteria. Iran J. Med. Sci. 37(2):72-73.

Kramer A, Scwebke I, Kampf G (2006). How long do nosocomial pathogens persist on inanimate surfaces? A systematic review. BMC Infect. Dis. 6:130.

Maley MP (2000). Compliance with handwashing infection control. Hosp. Epidemiol. 21: 4-6.

Marthi B, Fieland V P, Walter M, Seidler R J (1990). Survival of bacteria during aerosolization. Appl. Environ. Microbiol. 56:3463-3467.

Meltzer B (2003). Nosocomial Infections: Doctor's cell phones may spread hospital infections. Outpat. Surg. Mag.11:1-4.

Rajesh B, Rattan Li (2008). Infection and Disease. In: Essentials of Medical Microbiology. Peromila, editor. Jaypee Brothers Medical Publishers Ltd, pp. 65-68.

Rusin P, Maxwell S, Gerba C (2002). Comparative surface-to-hand and fingertip-to-mouth transfer efficiency of gram-positive bacteria, gramnegative bacteria, and phage. J. Appl. Microbiol. 93:585-592.

Rutala WA, Weber DJ (2004). Disinfection and Sterilization in Health Care Facilities:What Clinicians Need to Know. Health Care Epidemiol. 39:702-709.

Sadat-Ali M, Al-Omram AK, Azam Q, Bukari H, Al-Zahrani A, Al-Turki R, Al-Omram AS (2010). Bacterial flora on cell phones of health care providers in a teaching institution. Am. J. Infect. Control 38:404-405.

Singh A, Purohit B (2012). Mobile phones in hospital settings: a serious threat to infection. Occup. Health Saf. 81:42-44.

Singh S, Acharya S, Bhat M, Rao S.V, Pentapati SC (2010). Mobile phone hygiene: potential risks posed by use in the clinics of an Indian dental school. J. Dental Educ. 74:1153-1158.

Soto RG, Chu LF, Goldman JM, Rampil IJ, Ruskin KJ (2006). Commu- 
nication in critical care environments: mobile telephones improve patient care. Anesth. Anal. 102:535-541.

Srikanth P, Rajaram E, Sudharsanam S, Lakshmanan A, Mariappan US, Jagannathan K (2010). Mobile phones emerging threat for infection control. J. Infect. Prev. 11:87-90.

Struelens MJ, Dennis O, Rodriguez H (2004). Microbiology of Nosocomial infections: progress and changes. Microb. Infect. 6:10431048.

Tagoe DN, Gyande VK, Ansah EO (2011). Bacterial contamination of mobile phones: When your mobile phone could transmit more than just a call. Microbiology 2(10):WMC002294.

Tang JW (2009). The effect of environmental parameters on the survival of airborne infectious agents. J. R. Soc. Interface Suppl. 6 S737S746.

Tekerekoglu MS, Duman Y, Serinda A, Cuglan SS, Kaysadu H, Tunc E, Yakupogullari $Y$ (2011). Do mobile phones of patients, companions and visitors carry multidrug-resistant hospital pathogens? Am. J. Infect. Cont. 39(5): 379-381.
Ulger F, Esen S, Dilek A, Yanik K, Gunaydin M, Leblebicioglu H (2009). Are we aware how contaminated our mobile phones with nosocomial pathogens? Ann. Clin. Microbiol. Antimicrob. 8:7.

Wiener-Well Y, Galuty M, Rudensky B, Schlelsinger Y, Attias D, Yinnon AM (2011). Nursing and physician attire as possible source of nosocomial infections. Am. J. Infect. Control 39:555-559.

Willey JM, Sheerwood LM, Woolverton CJ (2009). Prescott's Principles of Microbiology. In: Microbial diseases and control. Connely JF, Brufl odt LA, editors. McGraw Hill.

Young JM, Naqvi M, Richards L (2005). Microbial contamination of hospital bed handsets. Am. J. Infect. Control 33:170-174. 